\title{
Impact of lens care solutions on protein deposition on soft contact lenses
}

DOI:

10.1097/OPX.0000000000000928

\section{Document Version}

Accepted author manuscript

Link to publication record in Manchester Research Explorer

\section{Citation for published version (APA):}

Omali, N. B., Heynen, M., Subbaraman, L. N., Papinski, D., Lakkis, C., Smith, S., Morgan, P., Berntsen, D. A., Nichols, J. J., Jones, L. W., Mathew, J. H., Cox, S. M., Bickle, K. M., Powell, D. R., Cox, J., Miller, W. L., WallaceTucker, A., Charrier, S., Chen, Y. J., ... Lada, M. W. (2016). Impact of lens care solutions on protein deposition on soft contact lenses. Optometry and Vision Science, 93(8), 963-972.

https://doi.org/10.1097/OPX.0000000000000928

\section{Published in:}

Optometry and Vision Science

\section{Citing this paper}

Please note that where the full-text provided on Manchester Research Explorer is the Author Accepted Manuscript or Proof version this may differ from the final Published version. If citing, it is advised that you check and use the publisher's definitive version.

\section{General rights}

Copyright and moral rights for the publications made accessible in the Research Explorer are retained by the authors and/or other copyright owners and it is a condition of accessing publications that users recognise and abide by the legal requirements associated with these rights.

\section{Takedown policy}

If you believe that this document breaches copyright please refer to the University of Manchester's Takedown Procedures [http://man.ac.uk/04Y6Bo] or contact uml.scholarlycommunications@manchester.ac.uk providing relevant details, so we can investigate your claim.

\section{OPEN ACCESS}




\section{Impact of Lens Care Solutions on Protein Deposition on Soft Contact Lenses}

Negar Babaei Omali, PhD, BOptom, Miriam Heynen, MSc, Lakshman N. Subbaraman, PhD, BSOptom, FAAO, Dominik Papinski, PhD, Carol Lakkis, PhD, BScOptom, PGCertOcTher, FAAO, Sarah L. Smith, MCOptom, BSc(Hons), Philip B. Morgan, PhD, MCOptom, FAAO, David A. Berntsen, OD, PhD, FAAO, Jason. J. Nichols, OD, PhD, MPH, FAAO, and Lyndon W. Jones, PhD, FCOptom, FAAO; for the Performance of Contact Lens Solutions Study Group

Centre for Contact Lens Research, School of Optometry and Vision Science, University of Waterloo, Ontario, Canada (NBO, MH, LNS, DP, LWJ), Johnson and Johnson Vision Care, Inc., Jacksonville, Florida (CL), Eurolens Research, University of Manchester, Manchester, United Kingdom (SLS, PBM), The Ocular Surface Institute, College of Optometry, University of Houston, Houston, Texas (DAB), and School of Optometry, University of Alabama, Birmingham, Birmingham, Alabama (JJN)

Short title: Lens Care Solutions and Protein Deposition

3 tables; 6 figures

Received: September 3, 2015; accepted May 25, 2016. 


\section{ABSTRACT}

Purpose. To evaluate the effect of four contemporary lens care solutions on total protein, total lysozyme and active lysozyme extracted from three contact lens materials. Methods. Adapted contact lens wearers were recruited at three sites and all subjects were randomly assigned to daily wear of either etafilcon A, galyfilcon A, or senofilcon A for 2 weeks. Four lens care solutions (Biotrue, OPTI-FREE PureMoist, RevitaLens OcuTec, and ClearCare) were used by each subject in random order with a new pair of lenses after a washout period between solutions of at least four days. After two weeks of daily wear, contact lenses were collected for analysis. Proteins were extracted from a subset of contact lenses $(n=568)$ and total protein, total lysozyme and lysozyme activity were quantified using a modified Bradford assay, an enzyme linked immunosorbent assay, and a micrococcal assay, respectively. Results. Higher levels of total protein were extracted from etafilcon A when used with Biotrue compared to other solutions $(p=0.0001)$. There were higher levels of total lysozyme extracted from galyfilcon A lenses when used with PureMoist than with Biotrue or ClearCare $(\mathrm{p}<0.006)$. Higher total lysozyme was extracted from senofilcon A when used with RevitaLens OcuTec compared to Biotrue $(\mathrm{p}=0.002)$. Lower lysozyme activity was recovered from senofilcon A lenses with RevitaLens OcuTec when compared to all other care solutions (all $\mathrm{p}<0.004$ ). When Biotrue, PureMoist or RevitaLens OcuTec were used, higher total lysozyme was extracted from galyfilcon A compared to senofilcon A $(\mathrm{p}<0.01)$. When RevitaLens OcuTec was used, higher levels of active lysozyme were extracted from galyfilcon A compared to senofilcon A $(\mathrm{p}=0.02)$. Conclusions. The ability of lens care solutions to remove protein from lenses varies depending upon the care solution composition and also the polymeric make-up of the contact lens material.

Key words: contact lens, protein deposition, lens care solutions, lysozyme 
The tear film contains over 1500 proteins, with lysozyme, albumin, lactoferrin and lipocalin comprising the major proteins. ${ }^{1}$ Lysozyme plays a critical role in the innate immunity of the tear film, by protecting the ocular surface against bacterial infection through enzymatic breakdown of bacterial cell walls. ${ }^{2}$ Lysozyme deposition on contact lenses has been widely studied, both in vitro and ex vivo. ${ }^{3-7}$ Protein deposition on contact lenses may result in contact lens discomfort, ${ }^{8}$ decreased vision ${ }^{9}$ and induction of inflammatory changes. ${ }^{10}$ Previous studies have indicated that protein deposition on poly-hydroxyethyl methacrylate (pHEMA)-based hydrogel contact lenses varied greatly in both in vitro and ex vivo experimental conditions, with the water content, ${ }^{11}$ surface charge ${ }^{12}$ and hydrophobicity ${ }^{13}$ of the lens material identified as important factors affecting deposition. Materials classified by the Food and Drug Administration (FDA) as being within group I ( $<50 \%$ water content, non-ionically charged surfaces) were shown to deposit significantly lower levels of total protein and lysozyme ${ }^{11,14,15}$ compared to materials classified within FDA group IV ( $>50 \%$ water content, ionically charged surfaces). ${ }^{16,17}$ This propensity for group IV lenses to deposit proteins, particularly those that are positively charged, has been reiterated by post-market in vitro and ex vivo studies of such materials. ${ }^{15,18,19}$

Silicone hydrogel (SH) lenses, which transmit higher amounts of oxygen than hydrogel materials, were commercialised in the late 1990s and reduced the signs of both acute and chronic hypoxia. ${ }^{20,21}$ These novel siloxane-based materials exhibited deposition profiles and preservative uptake behaviour which deviated from predictions based on the traditional FDA contact lens grouping system. ${ }^{22}$ This resulted in a new classification system for $\mathrm{SH}$ materials being suggested, in which traditional factors such as water content and surface charge would be maintained, but additional factors such as the presence of surface treatments are also considered. ${ }^{23}$ 
Contact lens care solutions are designed to provide adequate disinfection efficacy and enhanced comfort. They consist of several components, including preservatives (such as hydrogen peroxide, polyhexamethylene biguanide and polyquaternium-based systems), surfactants (such as poloxamers (Pluronic F87, Pluronic F127 and Pluronic 17R4) and poloxamines (Tetronic 1304 and Tetronic 1107)), chelating agents (ethylenediaminetetraacetic acid (EDTA), citrate, and hydroxyalkylphosphonate), ${ }^{24}$ and buffering agents. The combination and concentration of these agents influences the physical properties $(\mathrm{pH} \text {, viscosity, osmolality and surface tension })^{25}$ of the care solutions, which could potentially influence patient comfort during contact lens wear. To date, little evidence exists of the interaction between contemporary lens care systems and $\mathrm{SH}$ lenses, particularly on the topic of protein deposition.

The aim of this study was to determine the effect of various contact lens-solution combinations on deposition of total protein and lysozyme on three different contact lenses that were used with four different care systems and to further measure the activity of the deposited lysozyme.

\section{MATERIALS AND METHODS}

\section{Participants}

This clinical trial was conducted in compliance with the Declaration of Helsinki and was approved by the research ethics committee at each of the three investigative sites (University of Houston, Houston, Texas, USA; University of Manchester, Manchester, United Kingdom; and the Centre for Contact Lens Research, University of Waterloo, Waterloo, Ontario, Canada). Informed consent was obtained from all subjects prior to their enrolment in the study. Contact lenses were collected post-wear from two of the three clinical sites (University of Waterloo and 
University of Houston) for protein analyses. A total of 182 experienced (at least 8 hours per day, at least 5 days per week, for at least one month) spherical soft contact lens wearers between the ages of 18 and 69 years were enrolled across these two sites, and lenses from 152 participants only were eligible for analyses. The mean age of the subjects was $29 \pm 10$ years, and $69.8 \%$ were female. Exclusion criteria included active ocular infection, regular use of dry eye/rewetting drops and any clinically meaningful slit lamp findings contraindicating contact lens wear (e.g., $\geq$ Grade 3 finding of edema, corneal neovascularization, corneal staining, tarsal abnormalities, conjunctival injection, blepharitis/meibomian gland dysfunction) on the Efron grading scale or any other ocular abnormality that in the opinion of the investigator might have contraindicated contact lens wear). There were no restrictions as to gender or race/ethnicity. Contact lenses $(\mathrm{n}=608(152$ subjects $\mathrm{x} 1$ material $\mathrm{x} 4$ solutions $\mathrm{x} 1$ eye $))$ were collected for protein analysis at the University of Houston and the Centre for Contact Lens Research sites only. However, only data from 568 lenses could be analyzed, as 14 subjects discontinued from the study (accounting for 30 lenses) and a further 10 lenses with normalized protein values $>1$ (see later for data analysis) were also not included in the data analysis.

\section{Contact Lenses and Care Solutions}

Etafilcon A (ACUVUE 2), galyfilcon A (ACUVUE ADVANCE PLUS) and senofilcon A (ACUVUE OASYS) contact lenses (Johnson \& Johnson Vision Care, Inc., Jacksonville, Florida) were the investigational lens materials, with etafilcon A with LACREON Technology (1-DAY ACUVUE MOIST; Johnson \& Johnson Vision Care) lenses used in the washout periods between the different contact lens-care solution combinations. The rationale behind choosing senofilcon A and galyfilcon A lens materials was to test the performance of two silicone hydrogel lens 
materials that have different monomeric composition. Both these lenses incorporate an internal wetting agent, however, they have differing monomeric composition. Although galyfilcon A is now discontinued in some markets, it was not discontinued at the time that the study was conducted. The four care solutions used were Biotrue containing polyaminopropylbiguanide (PHMB) \& polyquaternium-1; OPTI-FREE PureMoist containing polyquaternium-1 \& myristamidopropyl dimethylamine; RevitaLens Ocutec containing alexidine \& polyquaternium-1 and ClearCare containing 3\% hydrogen peroxide. Subjects followed the manufacturers' instructions to clean and disinfect their lenses using the prescribed care solutions; ClearCare was a rinse only regimen, while all multipurpose solutions were a rub and rinse regimen. At every follow-up visit for each of the solution types, participants were asked about their lens wear compliance with both lenses and solutions since their last study visit, however, a formal assessment of compliance with lens care procedures was not conducted.

\section{Study Design and Wear Schedule}

After an initial washout period of at least 4 days, when subjects wore the 1-DAY ACUVUE MOIST daily disposable lenses and/or spectacles, each subject was randomly allocated to wear one of the three lens types. Participants were required to use a washout lens that eliminated the need for a cleaning procedure. To avoid any potential confounding factor based on solution use during washout, daily disposable lenses were chosen as the washout lens modality. A new lens of the assigned lens type was worn in combination with each of the four contact lens care solutions in random order over a period of 10 to 14 days per care solution. During this period, the subject was required to wear the study contact lenses for a minimum of eight hours a day for a minimum of five days per week. For subjects returning for evaluation after 10 days, if their lenses were not 
worn for at least 8 days prior to follow-up, they were not included in the analysis. There was a washout period of at least four days between each contact lens care solution during which daily disposable contact lenses and/or spectacles were worn. Subjects were fully masked to the contact lens type and partly masked to the care solution (as the difference in bottle and case designs prevented total masking for the care solutions), while clinical investigators were masked to the type of care solution only. Lab investigators were also aware of the contact lens type being collected, as the protocol for evaluating protein deposits differed depending on the contact lens material being assessed.

At the end of each contact lens-care solution wear period, the clinical investigator, wearing latexfree gloves, removed the right contact lens and placed it directly in a dry $7 \mathrm{~mL}$ polypropylene vial. Contact lens samples were stored at $-80{ }^{\circ} \mathrm{C}$ until protein analysis. Contact lenses collected from subjects' right eyes at the University of Houston were shipped to the Centre for Contact Lens Research for the analysis of total protein, total lysozyme and active lysozyme amounts. The contact lens-containing vials were placed in cryoboxes, which were surrounded with dry ice within insulated containers before shipping.

\section{Protein Analysis - Extraction and Lyophilization}

After thawing the lens at room temperature, 1.5 or $4 \mathrm{~mL}$ (dependent on the lens type) of 50 parts Acetonitrile: 50 parts MilliQ water: 0.2 parts $100 \%$ trifluoroacetic acid were added to the contact lens-containing vial. Four $\mathrm{mL}$ of extraction buffer was used to fully extract proteins from etafilcon A lens materials, whereas only $1.5 \mathrm{~mL}$ was required to extract protein from senofilcon A and galyfilcon A lenses. This difference in extraction protocol is due to the fact that etafilcon 
A-based materials deposit greater amounts of protein than silicone hydrogels and followed a previously published protocol. ${ }^{26}$ Samples were then placed on a shaker at room temperature for 24 hours. Afterwards, contact lens extracts were dried in a SpeedVac Concentrator (Savant, Halbrook, New York) for approximately $1.5-2$ hours at $35^{\circ} \mathrm{C}$ and the dried aliquots were then stored at $-80{ }^{\circ} \mathrm{C}$.

\section{Protein Analysis - Determination of Total Protein Deposition}

Total protein deposition on contact lenses was determined using a modified Bradford technique. ${ }^{6}$

${ }^{27}$ The dried samples were re-suspended in phosphate buffered saline (PBS). Along with $20 \mu \mathrm{L}$ of each of seven protein concentration standards from 0.025 to $0.5 \mu \mathrm{g} / \mu \mathrm{L}$, and $20 \mu \mathrm{L}$ of PBS as a control, the samples were processed through one $100 \%$ and two $90 \%$ alcohol washes, followed by drying with the SpeedVac for 10 minutes. The dried samples were re-suspended in $50 \mu \mathrm{L}$ of the Bio-Rad Protein Assay Reagent (Bio-Rad Laboratories, Mississauga, Ontario) and incubated at room temperature for 10 minutes. This was followed by placing the samples in boiling water for up to two minutes until no precipitates were visible. After cooling, $50 \mu \mathrm{L}$ of each sample were added to the wells of a 96-well plate. Subsequently, $150 \mu \mathrm{L}$ of $150 \mathrm{mM}$ sodium chloride $(\mathrm{NaCl})$ were added to each well and the absorbance at 595 and $450 \mathrm{~nm}$ were read with a plate reader (SpectraMax M5e Multi-Mode Microplate Reader, Molecular Devices, Inc, Sunnyvale, California).

\section{Protein Analysis - Determination of Total Lysozyme Deposition}

To measure total lysozyme from contact lens extracts, the human lysozyme enzyme linked immunosorbent assay (ELISA) kit (Calbiotech, Spring Valley, California) was used according to 
the manufacturer's instructions. To prepare the sample, one of the dried contact lens extract aliquots was re-suspended in the ELISA buffer and further diluted in order to measure the sample within the range of the standard curve $(40-0.125 \mathrm{ng} / \mathrm{mL})$. Twenty-five $\mu \mathrm{L}$ of the samples and standards were added to wells coated with an anti-lysozyme monoclonal antibody. This was followed by adding $100 \mu \mathrm{L}$ of anti-lysozyme conjugate solution to the wells. Samples were then incubated for 60 minutes at room temperature with shaking. After the incubation, wells were washed three times; upon the addition of the substrate, the absorbance at $450 \mathrm{~nm}$, which was proportional to the concentration of lysozyme, was read using a plate reader.

\section{Protein Analysis - Determination of Lysozyme Activity}

Lysozyme activity was determined using a modified micrococcal assay. ${ }^{28}$ Micrococcus lysodeikticus (ATCC No. 4698, Sigma-Aldrich, Oakville, Ontario) were incubated in PBS overnight at $4{ }^{\circ} \mathrm{C}$. The optical density of the bacterial solution was adjusted to be between 1.1 1.0 at $450 \mathrm{~nm}$. Human neutrophil lysozyme standards (Athens Research \& Technology Inc, Athens, Georgia) were prepared in $0.1 \mathrm{mg} / \mathrm{mL}$ bovine serum albumin between 4 and 0.125 $\mathrm{ng} / \mu \mathrm{L}$. Standards and contact lens extracts were then added to $1 \mathrm{~mL}$ of bacterial solution in a 48 well plate. The levels of active lysozyme in contact lens extract were determined and compared to a standard curve of human neutrophil lysozyme by determining the absorbance at $450 \mathrm{~nm}$ using the plate reader.

\section{Statistical Analysis}

All subjects met the minimum wearing time criterion. Fourteen subjects were discontinued from the study between the two sites. Levels of protein extracted from contact lenses were analyzed to 
test for the differences between the care solutions. The outcome variables were total protein, total lysozyme and lysozyme activity ( $\mu \mathrm{g} /$ Lens). Each parameter was analyzed using a linear mixed model to test for the difference between care solutions within each contact lens type. Contact lens type, solution and a contact lens by solution interaction were included in each model as fixed effect factors. Sequence of care solution and period were included where appropriate. An unstructured covariance matrix was used to model the correlation between measurements within the same subject/eye across visits. All statistical tests were two-sided and conducted at the 5\% level of significance. Adjustment for multiple pairwise comparisons between solutions across contact lens types was conducted using a Bonferroni correction. As the amounts of total protein or total lysozyme extracted from lenses are variable among subjects, extracted lysozyme and active lysozyme are presented as relative to the amount of total protein and total lysozyme respectively. Therefore, data for total lysozyme and active lysozyme were normalized to the total protein and total lysozyme respectively, prior to analysis. Three subjects (4 visits in total) from the Waterloo site and three subjects (4 visits in total) from the Houston site had normalized values greater than one; therefore, the data for those visits were discarded from all analyses. Data analysis was conducted using Statistica 12 (Statsoft Inc, Tulsa, Oklahoma) and SPSS 22 (International Business Machines Corporation, Armonk, New York).

\section{RESULTS}

\section{Total Protein}

Figure 1 (A-C) shows the total protein extracted from each lens type using each solution tested. There were higher levels of total protein extracted from etafilcon A lenses when used with Biotrue than with the use of other care solutions $\left(\mathrm{F}_{(3,347.585)}=38.44, \mathrm{p}=0.0001\right)$. None of the lens 
care solutions impacted the amount of total protein extracted from galyfilcon A or senofilcon A (all $\mathrm{p}>0.05$ ). Table 1 presents the summary of total protein $(\mu \mathrm{g} / \mathrm{lens})$ deposited on contact lenses used with different care solutions.

\section{Total Lysozyme}

Because the amount of total protein extracted from lenses is variable among subjects, lysozyme deposition is presented as relative to the amount of total protein. Figure 2 shows that the amounts of normalized total lysozyme extracted from etafilcon A were not significantly affected by any of the care solutions $(\mathrm{p}>0.05)$. There were statistically significant differences in levels of normalized total lysozyme extracted from galyfilcon A and senofilcon A lenses when used with different care solutions $\left(\mathrm{F}_{(3,336.911)}=8.53, \mathrm{p}<0.001\right)$. There were higher amounts of normalized total lysozyme extracted from galyfilcon A when used with PureMoist than when using Biotrue or ClearCare $(\mathrm{p}<0.006)$. Senofilcon A lenses in combination with RevitaLens OcuTec care solution had higher levels of normalized total extracted lysozyme when compared to Biotrue $(\mathrm{p}=0.002)$. There were no other differences observed.

Table 2 summarizes the normalized total lysozyme (proportion of total protein) extracted from contact lenses when used with each care solution. Figure 3 (A-C) presents the absolute values ( $\mu \mathrm{g} / \mathrm{lens})$ of lysozyme extracted from each contact lens type.

\section{Lysozyme Activity}

Because the amount of total lysozyme deposition on lenses is variable among subjects, active lysozyme deposition is presented as relative to the amount of total lysozyme. Therefore, data for 
active lysozyme was normalized to the total lysozyme prior to analysis. Normalized active lysozyme is defined as the proportion of active lysozyme to total lysozyme. Figure 4 shows that the amounts of normalized active lysozyme extracted from etafilcon A and galyfilcon A were not affected when any of the four solutions were used to clean the contact lenses (all $\mathrm{p}>0.05$ ). However, senofilcon A in combination with RevitaLens OcuTec had significantly lower normalized active lysozyme when compared to other care solutions $\left(\mathrm{F}_{(3,381.446)}=7.750, \mathrm{p}<0.004\right)$. The percentage of active lysozyme deposition on contact lenses is shown in Figure 5. Table 3 summarizes the normalized active lysozyme (proportion of total lysozyme) extracted from each contact lens type when used with the care solutions tested. Figure 6 (A-C) presents the absolute values ( $\mu \mathrm{g} / \mathrm{lens})$ for the amount of active lysozyme extracted from each contact lens type tested.

\section{DISCUSSION}

In this study, the protein removal ability of four different solutions and their impact on the activity of lysozyme were examined on three contact lens materials. It is interesting to note that when examining the total amount of protein recovered from these materials, there was no effect of solution type for the two SH materials, senofilcon A and galyfilcon A (Figure 1B and C). In contrast, there was a statistically significant increase in the amount of protein extracted from the FDA group IV hydrogel material (etafilcon A) when subjects used Biotrue. The observation that the etafilcon A-Biotrue combination led to the greatest amount of protein deposition may be related to the differences in surfactants or wetting agents between the solutions (Figure 1A and Table 1). The Biotrue solution also contains sulfobetaine, a compound previously used in laboratories to renature proteins, possibly allowing for greater overall deposition of tear film protein. $^{29}$ 
The greater total protein extracted from etafilcon A lenses in combination with the Biotrue solution does not appear to be due to an increase in lysozyme deposition, as analysis of the normalized lysozyme extracted from etafilcon A yielded no statistically significant differences between the four solutions (Figure 2). Given these results, it is worth investigating other major proteins that deposit on etafilcon A lenses when used with these care solutions to have better insights of their proportions to total protein. Significant differences in lysozyme deposition were found when galyfilcon A was used with PureMoist, as compared to both Biotrue and ClearCare $(p<0.006$; Figure 2). Differences in lysozyme deposition were also observed with the senofilcon A material when used with RevitaLens OcuTec, compared to its use with Biotrue $(p=0.002$; Figure 2).

When examining normalized lysozyme activity, it was determined that a combination of senofilcon A with the RevitaLens OcuTec had significantly lower active lysozyme than contact lenses cleaned with the other care solutions $(\mathrm{p}<0.01$; Figure 4$)$.

The lack of any consistent pattern in lens-solution combination on the amount of protein extracted from the materials or the activity of the protein examined speaks to the difficulty in predicting these interactions between the lens, solution and the wearer. This finding is in agreement with the study by Zhao et al., ${ }^{30}$ in which they suggested that the efficacy of care solutions to remove lipid and protein deposits varies with lens material. Emch and Nichols ${ }^{31}$ also quantified the amount of protein extracted from two different SH materials (galyfilcon A and lotrafilcon B) that were used with several care solutions, and reported higher levels of protein 
extracted from lotrafilcon B compared to senofilcon A. They attributed this finding to differences in solution efficacy. ${ }^{31}$

Contact lens wear is one of the causes for evaporative dry eye disease and aqueous deficient dry eye is common after 40 years, especially in women. In the current study, only $16 \%$ of subjects were over 40 years of age and among the participants that were over $40,76 \%$ were female and $24 \%$ were males. As we had only $16 \%$ of subjects over 40 , we did not have a sufficient number of older subjects to analyze the data according to age, and this would be worthwhile investigating in a future study.

It is interesting to note that the etafilcon A-Biotrue combination resulted in the greatest amount of protein deposition. However, there were no differences in protein deposition when comparing Biotrue to the other lens care solutions and the silicone hydrogel materials. A lens care solution is made up of several components including biocides, surfactants, rewetting agents, chelating agents, and buffering agents. The cleaning and disinfection ability of any care solution is dependent on various factors such as the interaction of these various components with the lens material and the cleaning ability is particularly dependent on the ability of the components to break the bonds between the protein and the contact lens material. It is very difficult to hypothesize that one particular component within these solutions plays a major role over the other in the removal of any specific deposited component. The trend towards the development of ever more complex care solutions containing more than one preservative/disinfecting agent, in addition to proprietary formulations, aims to increase comfort during contact lens wear. The three multipurpose solutions examined in this study (Biotrue, OPTI-FREE PureMoist and 
RevitaLens Ocutec) are all relatively new to the contact lens market, and all use dual disinfectants with a proprietary mix of surfactants and wetting agents. To date, very little data exists on the ability of these new care systems to impact protein deposition, and this study showed that there were certain contact lens-care solution combinations that appeared to reduce protein deposition.

\section{CONCLUSIONS}

The ability of lens care solutions to control protein deposition on different contact lens materials varies, and depends upon the care solution composition and also the polymeric make-up of the contact lens material. These results show that certain combinations of care solutions and contact lenses can impact the amounts of protein that are extracted from worn lenses and can result in differences in biological activity of deposited lysozyme; however, no consistent patterns were observed. The long-term consequences of these variations remain to be ascertained, before specific recommendations regarding optimal lens care solution-material combinations can be made.

\section{ACKNOWLEDGMENTS}

This study was sponsored by Johnson and Johnson Vision Care, Inc., Jacksonville, Florida. The authors would like to thank Sarah Guthrie for her editorial assistance.

Over the past three years, research support or lectureship honoraria have been received from the following companies as indicated by study site. University of Houston: Alcon, Allergan, Bausch

+ Lomb, Johnson \& Johnson Vision Care, Menicon. University of Manchester: Alcon, Bausch + 
Lomb, CooperVision, Essilor, Johnson \& Johnson Vision Care, Sauflon Pharmaceuticals,

Ultravision. University of Waterloo: Advanced Vision Research, Alcon, AlgiPharma, Allergan,

CIBA Vision, CooperVision, Essilor, Johnson \& Johnson Vision Care, Ocular Dynamics,

Oculus, Ocusense, TearScience, and Visioneering Technologies. LWJ is a consultant and/or

serves on an advisory board for Alcon and J\&J Vision Care.

\author{
Performance of Contact Lens Solutions Study Group \\ University of Houston Site \\ Jason J. Nichols, OD, MPH, PhD, FAAO; David A. Berntsen, OD, PhD, FAAO; Jessica H. Mathew, OD, PhD, \\ FAAO; Stephanie M. Cox, OD, FAAO; Katherine M. Bickle, OD, MS; Daniel R. Powell, OD, PhD; Jared Cox, OD; \\ William L. Miller, OD, PhD, FAAO; Ashley Wallace-Tucker, OD, FAAO; Sabrina Charrier, OD, FAAO; Yi-Ju \\ (Tina) Chen, BA, MA; Laura Cardenas; Sonia Huerta, AAS; Karen Dionne, BS
}

\title{
University of Manchester Site
}

Philip B. Morgan, PhD, MCOptom, FAAO, FBCLA; Carole Maldonado-Codina, PhD, MCOptom, FAAO, FBCLA; Andrew J. Plowright, BSc(Hons), MSc, FBCLA; Gillian F. Howarth, BSc(Hons), MCOptom; Neil Chatterjee, MSc, MCOptom; Aftab Mirza, MSc, MCOptom; Sarah Smith, BSc(Hons), MCOptom

\section{University of Waterloo Site}

Lyndon W. Jones, PhD, FCOptom, FAAO; Clinical Team: Kathy Dumbleton, PhD, MCOptom, FAAO; Marc Schulze, PhD, Dipl Ing (AO), FAAO; Amir M. Moezzi, MSc, OD; Doerte Luensmann, PhD, Dipl. Ing. (AO), FAAO; William Ngo, BSc, OD, FAAO; Lindsay Paquette, BSc, OD; Sruthi Srinivasan, PhD, BS Optom, FAAO; Jalaiah Varikooty, MSc, BMed; Jane Johnson; Marina Simpson, BRT, Brad; Leona Voss; Lynn Ryan, BA; Nadeera Careless; Alexandra Smith; Laboratory Team: Lakshman Subbaraman, PhD, BS Optom, FAAO; Miriam Heynen, MSc; Jaya Dantam, PhD, BOptom; David McCanna, PhD; Negar Babaei Omali, PhD, BOptom; Dominik Papinski, $\mathrm{PhD}$

Johnson \& Johnson Vision Care, Inc.

Sheila B. Hickson-Curran, BSc(Hons), MCOptom, FAAO, FBCLA; Carol Lakkis, BScOptom, PhD, PGCertOcTher, FAAO, FACO, FBCLA; Youssef Toubouti, MSc; Zohra Fadli, PhD; Mark Witold Lada, PhD 


\section{REFERENCES}

1. Zhou L, Zhao SZ, Koh SK, Chen L, Vaz C, Tanavde V, Li XR, Beuerman RW. In-depth analysis of the human tear proteome. J Proteomics 2012;75:3877-85.

2. Fleming A. On a remarkable bacteriolytic element found in tissues and secretions. Proc Roy Soc London (B) 1922;93:306-17.

. Boone A, Heynen M, Joyce E, Varikooty J, Jones L. Ex vivo protein deposition on biweekly silicone hydrogel contact lenses. Optom Vis Sci 2009;86:1241-9.

4. Glasier MA, Keech A, Sheardown H, Subbaraman LN, Jones L. Conformational and quantitative characterization of lysozyme extracted from galyfilcon and senofilcon silicone hydrogel contact lenses. Curr Eye Res 2008;33:1-11.

5. Jones L, Mann A, Evans K, Franklin V, Tighe B. An in vivo comparison of the kinetics of protein and lipid deposition on group II and group IV frequent-replacement contact lenses. Optom Vis Sci 2000;77:503-10.

6. Subbaraman LN, Woods J, Teichroeb JH, Jones L. Protein deposition on a lathe-cut silicone hydrogel contact lens material. Optom Vis Sci 2009;86:244-50.

7. Omali NB, Zhao Z, Zhu H, Tilia D, Willcox MD. Quantification of individual proteins in silicone hydrogel contact lens deposits. Mol Vis 2013;19:390-9.

8. Jones L, Franklin V, Evans K, Sariri R, Tighe B. Spoilation and clinical performance of monthly vs. three monthly Group II disposable contact lenses. Optom Vis Sci 1996;73:1621.

9. Gellatly KW, Brennan NA, Efron N. Visual decrement with deposit accumulation of HEMA contact lenses. Am J Optom Physiol Opt 1988;65:937-41. 
10. Skotnitsky CC, Naduvilath TJ, Sweeney DF, Sankaridurg PR. Two presentations of contact lens-induced papillary conjunctivitis (CLPC) in hydrogel lens wear: local and general. Optom Vis Sci 2006;83:27-36.

11. Minarik L, Rapp J. Protein deposits on individual hydrophilic contact lenses: effects of water and ionicity. CLAO J 1989;15:185-8.

12. Garrett Q, Chatelier RC, Griesser HJ, Milthorpe BK. Effect of charged groups on the adsorption and penetration of proteins onto and into carboxymethylated poly(HEMA) hydrogels. Biomaterials 1998;19:2175-86.

13. Castillo EJ, Koenig JL, Anderson JM. Characterization of protein adsorption on soft contact lenses. IV. Comparison of in vivo spoilage with the in vitro adsorption of tear proteins. Biomaterials 1986;7:89-96.

14. Wedler FC. Analysis of biomaterials deposited on soft contact lenses. J Biomed Mater Res $1977 ; 11: 525-35$.

15. Subbaraman LN, Glasier MA, Senchyna M, Sheardown H, Jones L. Kinetics of in vitro lysozyme deposition on silicone hydrogel, PMMA, and FDA groups I, II, and IV contact lens materials. Curr Eye Res 2006;31:787-96.

16. Zhang S, Borazjani RN, Salamone JC, Ahearn DG, Crow SA, Jr., Pierce GE. In vitro deposition of lysozyme on etafilcon A and balafilcon A hydrogel contact lenses: effects on adhesion and survival of Pseudomonas aeruginosa and Staphylococcus aureus. Contact Lens Anterior Eye 2005;28:113-9.

17. Luensmann D, Heynen M, Liu L, Sheardown H, Jones L. The efficiency of contact lens care regimens on protein removal from hydrogel and silicone hydrogel lenses. Mol Vis 2010;16:79-92. 
18. Suwala M, Glasier MA, Subbaraman LN, Jones L. Quantity and conformation of lysozyme deposited on conventional and silicone hydrogel contact lens materials using an in vitro model. Eye Contact Lens 2007;33:138-43.

19. Senchyna M, Jones L, Louie D, May C, Forbes I, Glasier MA. Quantitative and conformational characterization of lysozyme deposited on balafilcon and etafilcon contact lens materials. Curr Eye Res 2004;28:25-36.

20. Sweeney DF. Clinical signs of hypoxia with high-Dk soft lens extended wear: is the cornea convinced? Eye Contact Lens 2003;29:S22-5.

21. Tighe B. Silicone hydrogel materials - how do they work ? In: Sweeney D, ed. Silicone Hydrogels: The Rebirth of Continuous Wear Contact Lenses. Oxford: ButterworthHeinemann; 2000:1-21.

22. Green JA, Phillips KS, Hitchins VM, Lucas AD, Shoff ME, Hutter JC, Rorer EM, Eydelman MB. Material properties that predict preservative uptake for silicone hydrogel contact lenses. Eye Contact Lens 2012;38:350-7.

23. Hutter JC, Green JA, Eydelman MB. Proposed silicone hydrogel contact lens grouping system for lens care product compatibility testing. Eye Contact Lens 2012;38:358-62.

24. Jones L, Christie C. Soft contact lens solutions review: part 2 - modern generation care systems. Optom Practice 2008;9:43-62.

25. Jones L, Brennan NA, Gonzalez-Meijome J, Lally J, Maldonado-Codina C, Schmidt TA, Subbaraman L, Young G, Nichols JJ, Members of the TFOS International Workshop on Contact Lens Discomfort. The TFOS International Workshop on Contact Lens Discomfort: report of the contact lens materials, design, and care subcommittee. Invest Ophthalmol Vis Sci 2013;54:TFOS37-70. 
26. Subbaraman LN, Glasier MA, Senchyna M, Sheardown H, Jones L. Extraction efficiency of an extraction buffer used to quantify lysozyme deposition on conventional and silicone hydrogel contact lens materials. Eye Contact Lens 2007;33:169-73.

27. Bradford MM. A rapid and sensitive method for the quantitation of microgram quantities of protein utilizing the principle of protein-dye binding. Anal Biochem 1976;72:248-54.

28. Subbaraman LN, Glasier MA, Varikooty J, Srinivasan S, Jones L. Protein deposition and clinical symptoms in daily wear of etafilcon lenses. Optom Vis Sci 2012;89:1450-9.

29. Wright EA, Payne KA, Jowitt TA, Howard M, Morgan PB, Maldonado-Codina C, Dobson CB. Preservation of human tear protein structure and function by a novel contact lens multipurpose solution containing protein-stabilizing agents. Eye Contact Lens 2012;38:3642.

30. Zhao Z, Carnt NA, Aliwarga Y, Wei X, Naduvilath T, Garrett Q, Korth J, Willcox MD. Care regimen and lens material influence on silicone hydrogel contact lens deposition. Optom Vis Sci 2009;86:251-9.

31. Emch AJ, Nichols JJ. Proteins identified from care solution extractions of silicone hydrogels. Optom Vis Sci 2009;86: 123-31.

Corresponding author:

Negar Babaei Omali

Centre for Contact Lens Research

School of Optometry and Vision Science University of Waterloo 200 University Ave W Waterloo ON N2L 3G1 CANADA e-mail: nbabaeio@uwaterloo.ca 
Table 1. Summary of total protein ( $\mu \mathrm{g} / \mathrm{lens})$ deposited on contact lenses with different care solutions.

\begin{tabular}{ccc}
\hline Contact Lens & Care Solution & Mean \pm SD \\
\hline & Biotrue & $1779.9 \pm 566.2$ \\
etafilcon A & OPTI-FREE PureMoist & $1265.5 \pm 356.1$ \\
(ACUVUE 2) & RevitaLens OcuTec & $1242.0 \pm 503.9$ \\
& ClearCare & $1185.1 \pm 338.0$ \\
\hline galyfilcon A & Biotrue & $7.3 \pm 3.0$ \\
(ACUVUE Advance Plus) & OPTI-FREE PureMoist & $8.8 \pm 4.4$ \\
& RevitaLens OcuTec & $7.5 \pm 3.4$ \\
senofilcon A & ClearCare & $8.4 \pm 3.5$ \\
\hline (ACUVUE OASYS) & Biotrue & $7.6 \pm 3.8$ \\
& OPTI-FREE PureMoist & $8.1 \pm 5.8$ \\
& RevitaLens OcuTec & $6.8 \pm 3.4$ \\
& ClearCare & $7.5 \pm 4.4$ \\
\hline
\end{tabular}


Table 2. Summary of normalized total lysozyme deposited on contact lenses with each care solution.

\begin{tabular}{ccc}
\hline Contact Lens & Care Solution & Mean \pm SD \\
\hline & Biotrue & $0.68 \pm 0.18$ \\
etafilcon A & OPTI-FREE PureMoist & $0.71 \pm 0.14$ \\
(ACUVUE 2) & RevitaLens OcuTec & $0.72 \pm 0.16$ \\
& ClearCare & $0.72 \pm 0.22$ \\
\hline galyfilcon A & Biotrue & $0.24 \pm 0.13$ \\
(ACUVUE Advance Plus) & OPTI-FREE PureMoist & $0.35 \pm 0.23$ \\
& RevitaLens OcuTec & $0.31 \pm 0.17$ \\
& ClearCare & $0.24 \pm 0.18$ \\
\hline senofilcon A & Biotrue & $0.13 \pm 0.10$ \\
(ACUVUE OASYS) & OPTI-FREE PureMoist & $0.16 \pm 0.07$ \\
& RevitaLens OcuTec & $0.22 \pm 0.24$ \\
& ClearCare & $0.18 \pm 0.16$ \\
\hline
\end{tabular}


Table 3. Summary of normalized active lysozyme deposited on contact lenses with each care solution

\begin{tabular}{ccc}
\hline Contact Lens & Care Solution & Mean \pm SD \\
\hline & Biotrue & $0.68 \pm 0.24$ \\
etafilcon A & OPTI-FREE PureMoist & $0.68 \pm 0.22$ \\
(ACUVUE 2) & RevitaLens OcuTec & $0.65 \pm 0.21$ \\
& ClearCare & $0.68 \pm 0.22$ \\
\hline & Biotrue & $0.58 \pm 0.16$ \\
galyfilcon A & OPTI-FREE PureMoist & $0.55 \pm 0.22$ \\
(ACUVUE Advance Plus) & RevitaLens OcuTec & $0.53 \pm 0.20$ \\
& ClearCare & $0.60 \pm 0.17$ \\
\hline & Biotrue & $0.58 \pm 0.20$ \\
senofilcon A & OPTI-FREE PureMoist & $0.54 \pm 0.19$ \\
(ACUVUE OASYS) & RevitaLens OcuTec & $0.43 \pm 0.19$ \\
& ClearCare & $0.55 \pm 0.22$ \\
\hline
\end{tabular}




\section{FIGURE LEGENDS}

Figure 1. (A-C) Total protein extracted from all contact lens materials when used with different care solutions; * indicated that higher level of total protein was extracted from etafilcon A lenses when used with Biotrue compared to the use of other care solutions.

Figure 2. Total normalized lysozyme extracted from contact lenses when used with each care solution; * indicated that galyfilcon A had significantly higher amounts of normalized total lysozyme when used with PureMoist compared to the use of Biotrue or ClearCare $(\mathrm{p} \leq 0.006) ; *$ indicated that senofilcon A used with RevitaLens OcuTec had higher levels of normalized total lysozyme compared to Biotrue.

Figure 3. (A-C) Total lysozyme deposition ( $\mu \mathrm{g} / \mathrm{lens})$ on contact lenses when used with each care solution.

Figure 4. Normalized active lysozyme extracted from contact lenses when used with each care solution; * indicated that senofilcon A in combination with RevitaLens OcuTec had significantly lower normalized active lysozyme when compared to other care solutions $(\mathrm{p}<0.004)$.

Figure 5. Percentage of active lysozyme deposition on contact lenses when used with each care solution. * indicated senofilcon A in combination with RevitaLens OcuTec had significantly lower active lysozyme when compared to other care solutions ( $<<0.004)$.

Figure 6. (A-C) Active lysozyme ( $\mu \mathrm{g} / \mathrm{lens})$ extracted from contact lenses when used with each care solution. 
Figures $1-6$ finalKAZ

A
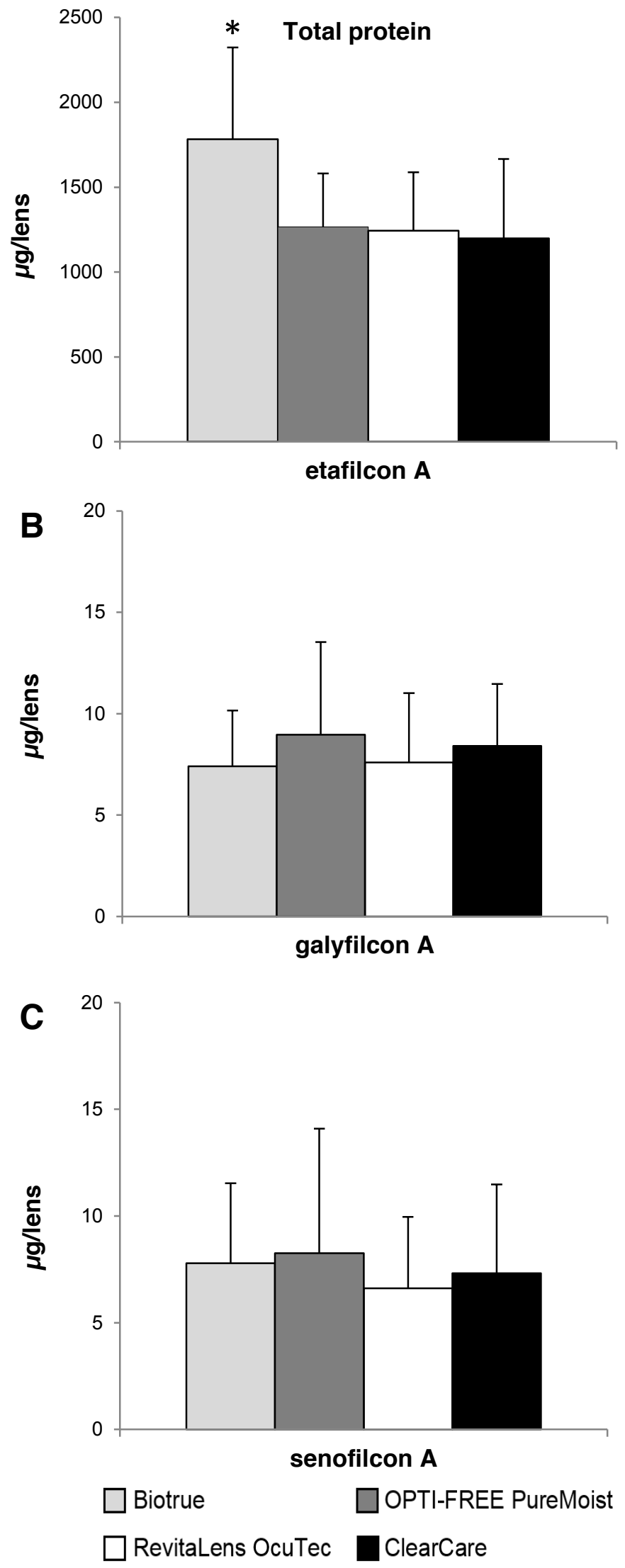

Figure 1 


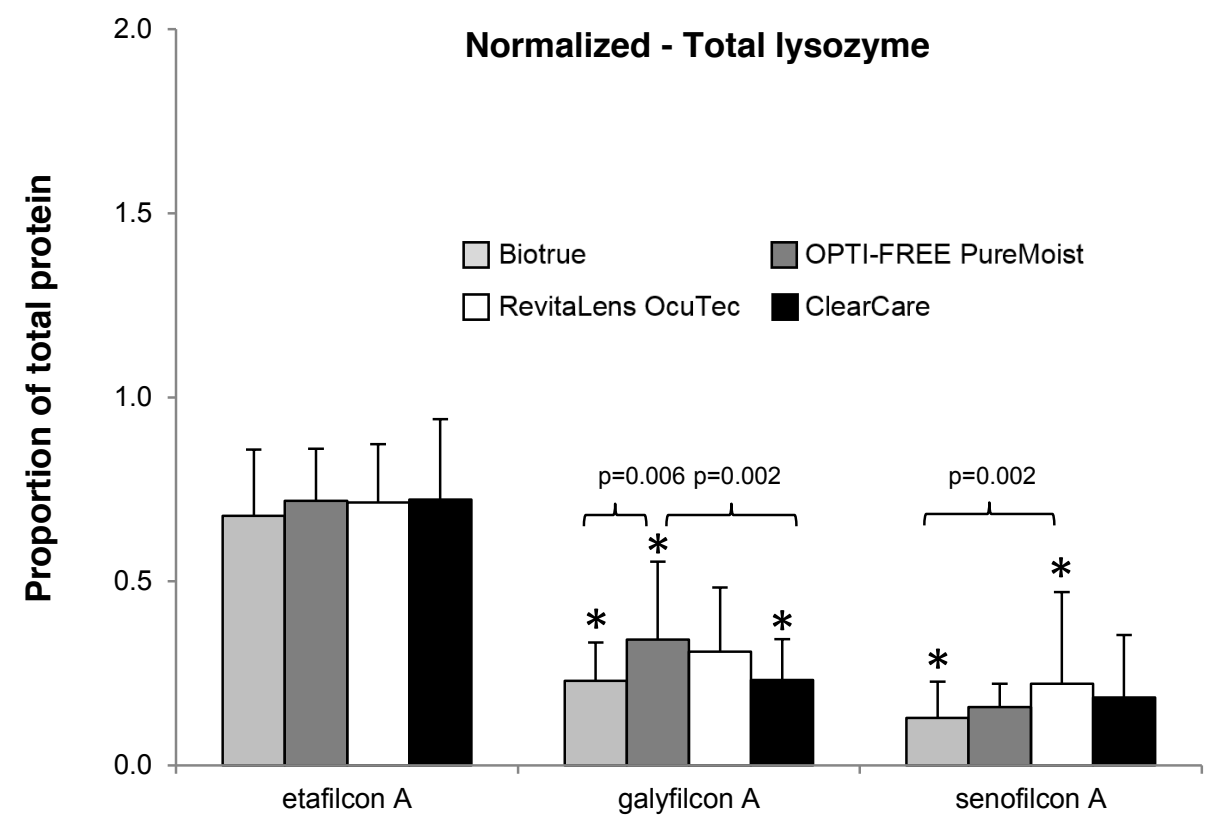

Figure 2 

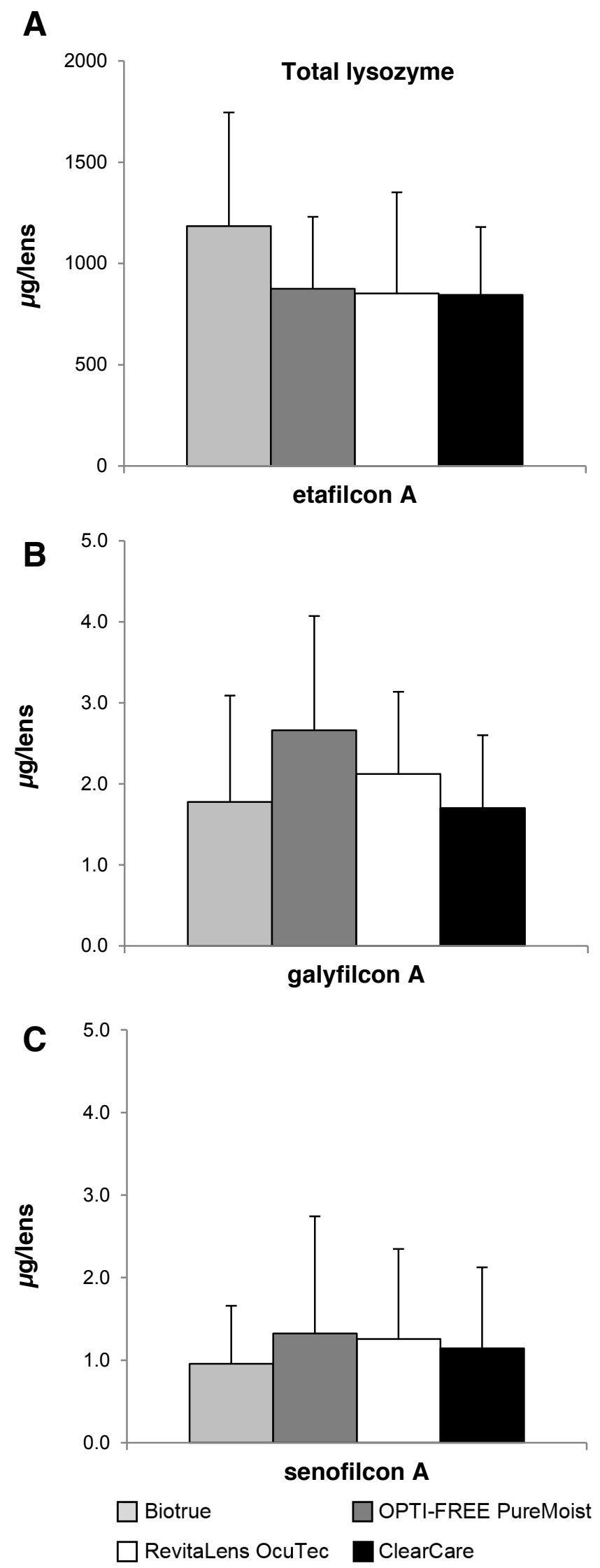

Figure 3 


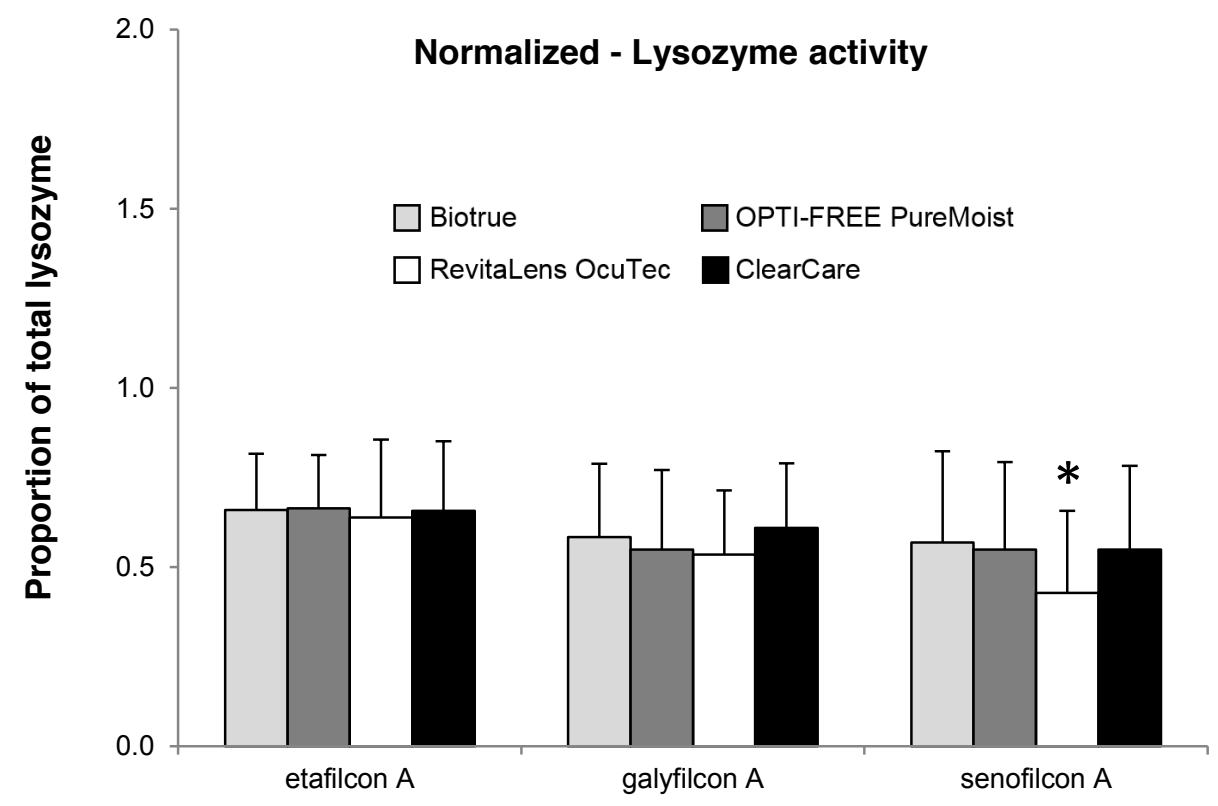

Figure 4 


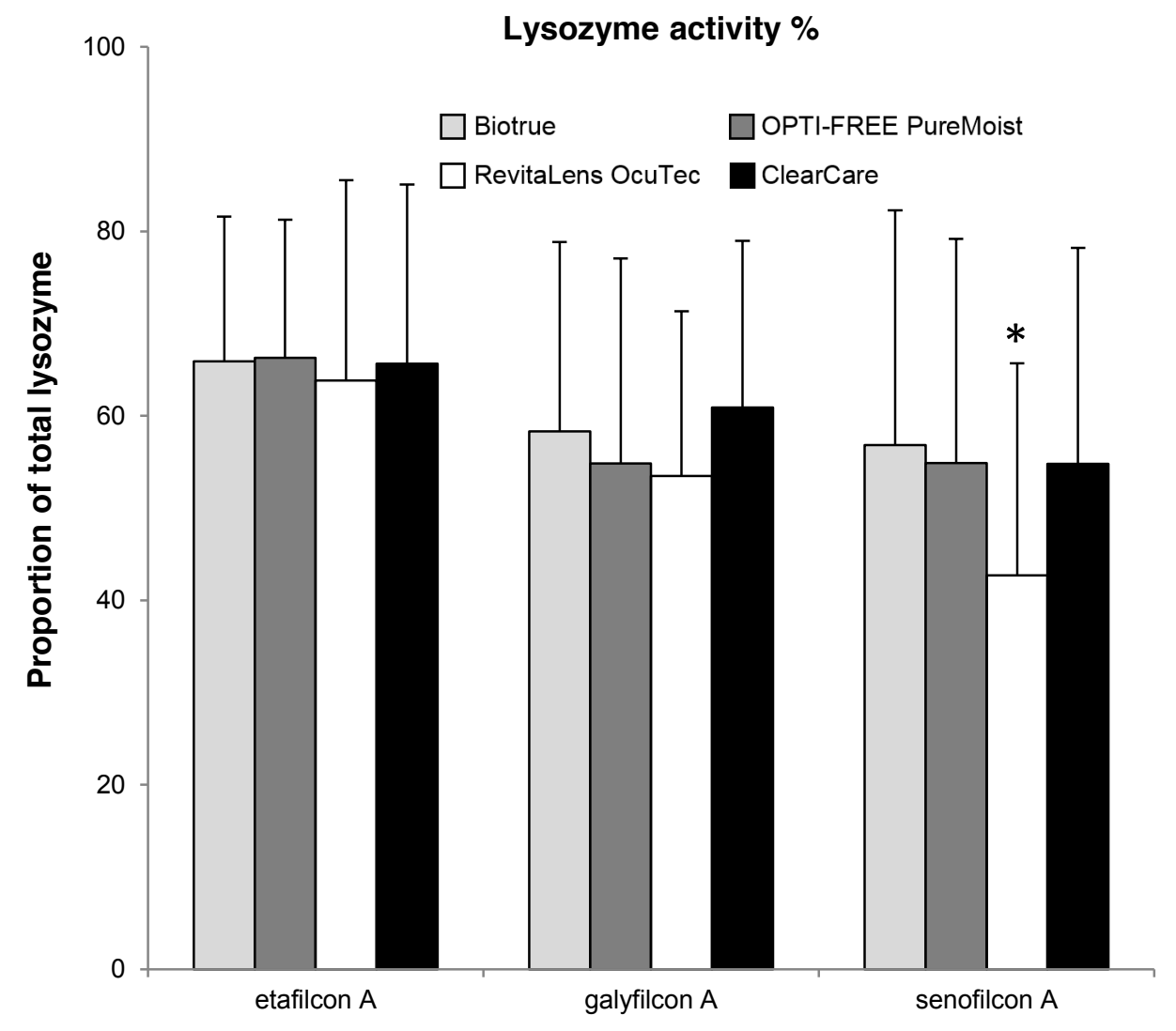

Figure 5 
A
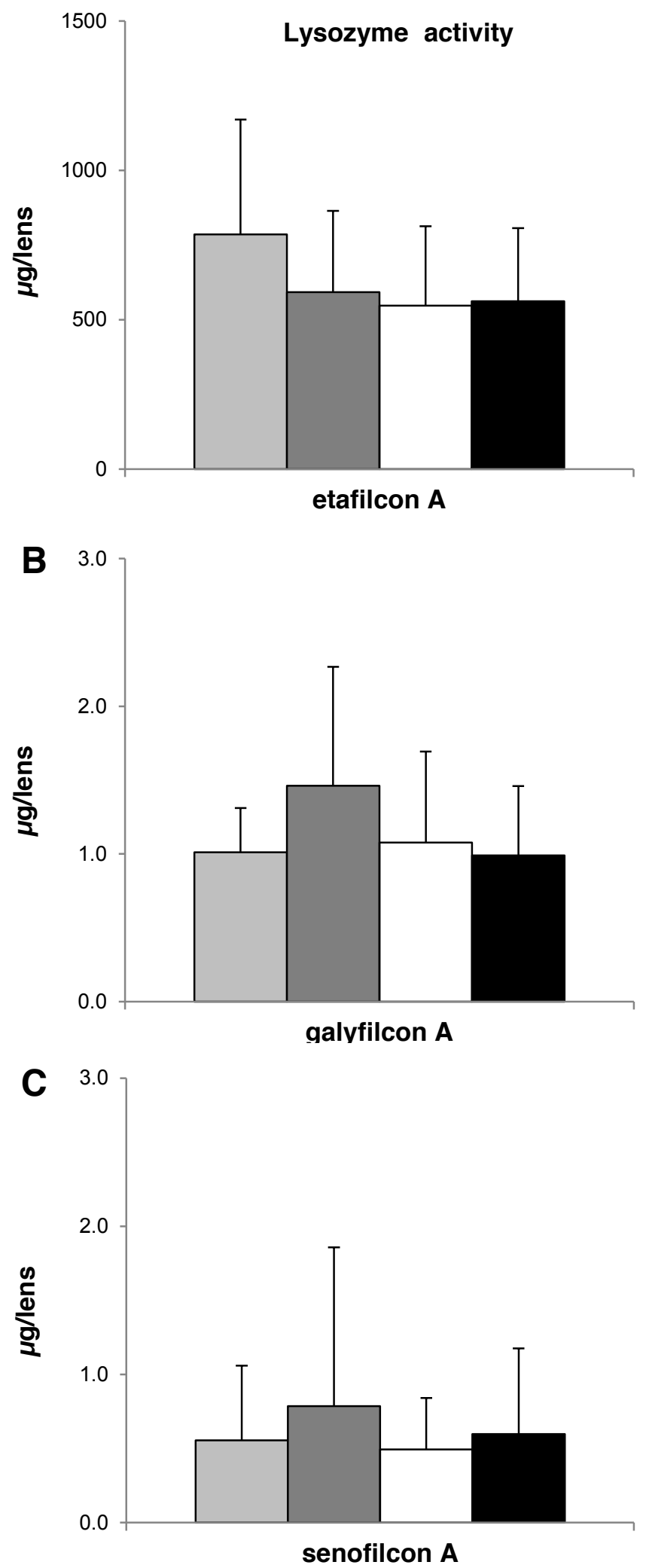

Figure 6 $\square$ Biotrue $\square$ OPTI-FREE PureMoist $\square$ RevitaLens OcuTec $\square$ ClearCare 


\title{
\begin{tabular}{l|l} 
B. Wolters Kluwer & $\begin{array}{l}\text { Lippincott } \\
\text { Health }\end{array}$
\end{tabular}
}

\author{
LICENSING AGREEMENT \\ Optometry and Vision Science / American Academy of Optometry \\ Lippincott Williams \& Wilkins, a business of Wolters Kluwer Health
}

This Agreement is made by and between Lippincott Williams \& Wilkins, a business of Wolters Kluwer Health, Inc. a corporation organized under the laws of the State of New York and having as one of its principal offices a location at Two Commerce Square 2001 Market Street Philadelphia, PA 19103 USA (referred to in this Agreement as "The Publisher") and LAKSHMAN SURDARQMA $\sim$ (insert name - referred to in this agreement as "The Copyright Omner").

For the Content:

OVS Announces image file name, as submitted to the Editorial office

OVS ANNOUNCES mahE

Content to appear in:

OVS manuscript number/corresponding aut hor's

surname OVS 15499 , BABACI OMALI

\section{LICENSE TERMS}

The Copyright Owner hereby grants Lippincott Williams \& Wilkins and the American Academy of Optometry a non-exclusive license to publish the Content, to copy the content, for commercial and non-commercial use, to issue copies of the content, to the public and to communicate the content, to the public, in electronic form, in all languages. For the purposes of this Agreement, the Content, is considered to include the image(s) submitted for publication.

The Copyright Owner grants Lippincott Williams \& Wilkins the right to reproduce Content in the journal publication optometry and vision science. 
SIGNED AND DATED:

2) March 2016

[Date]

LAKSHMAN SUBBARAMAN

[Print Name]

NSlubher

[Sign Name]

UPLOAD W TH YOUR REVISI ON, OR EMAIL TO: Kurt A. Zadnik at ovs@Osu.edu. 